\title{
Diagnostic and prognostic implications of the unfolding molecular biology of bone and soft tissue tumours
}

\author{
J F Graadt van Roggen, J V M G Bovée, J Morreau, P C W Hogendoorn
}

\begin{abstract}
Sarcomas account for approximately $1-2 \%$ of human malignant disease and are relatively uncommon. Histopathological study of these mesenchymal tumours at light microscopic and ultrastructural level may not always provide an unambiguous diagnosis. It has become apparent with the identification of increasing numbers of tumour specific genetic alterations that (cyto)genetic evaluation could become a very helpful adjunct to histopathological assessment in reaching a correct diagnosis. Thus, once the different tumour types can be accurately identified and classified, more meaningful clinical trials can be initiated to evaluate and select optimal methods of management. In addition, an increasing awareness and understanding of the molecular changes associated with, and the genetic variability in, the various tumour groups is beginning to provide important new information about clinical progression and prognosis.

(F Clin Pathol 1999;52:481-489)
\end{abstract}

Keywords: bone tumours; soft tissue tumours; molecular biology

Bone and soft tissue tumours are a heterogeneous and complex group of lesions arising as a result of neoplastic transformation within structures derived from the embryological mesoderm and neuroectoderm, ${ }^{1}$ and currently classified on a histogenetic basis according to the mature tissues they might resemble. ${ }^{2}$ They represent a major group of tumours distinct from those neoplasms having an epithelial, haematopoietic, or central neurogenic origin. Benign lesions seen in a hospital setting outnumber their malignant counterparts by a margin of approximately 100:1, with an annual incidence of about $300 / 100000$ of the population. ${ }^{3}$ This is almost certainly a conservative estimate since many of the benign lesions in the general population are not biopsied. Malignant tumours (sarcomas) are rare and represent about $1-2 \%$ of all cancers and cancer deaths in adults; in the USA roughly 5000 new cases are diagnosed annually, as compared with 90000 cases of lung cancer and
180000 of breast cancer. ${ }^{4}$ In children, however, sarcomas are relatively more common, accounting for approximately $10 \%$ of all malignant solid tumours. ${ }^{4}$ Furthermore, there appears to be an increasing incidence of soft tissue sarcomas, although this may merely represent improved diagnostic capability and an increasing interest in this group of lesions.

Primary malignant bone tumours are considerably rarer than soft tissue sarcomas, accounting for less than $1 \%$ of all cancer deaths ${ }^{4}$; involvement of the skeletal tissues by metastatic disease, however, is seen far more frequently (own observations).

Bone and soft tissue tumours often present diagnostic difficulties for clinician and pathologist alike and, despite the many advances in diagnostic histological techniques, the histogenesis of many of these neoplasms remains difficult to establish. Published work has shown that disparity between the original histopathological diagnosis and subsequent expert review could be present in as many as $25 \%$ of malignant mesenchymal lesions. ${ }^{5}$ Thus our ability to initiate meaningful clinical trials to evaluate optimal methods of treatment-as well as to identify possible prognostic variables - for the various tumour types may be limited.

It has become apparent over the last decade that many malignant bone and soft tissue tumours carry chromosomal aberrations detectable at a cytogenetic or molecular level, several of which appear to be non-random and associated with specific tumour types. ${ }^{6-9}$ These alterations, especially when compared with the genetic aberrations described in the far more prevalent carcinoma group, appear to be less complicated and consequently more accessible to study, resulting in a rapid acquisition of new information about the molecular genetics of sarcomas.

Since many high grade sarcomas may present morphologically as poorly differentiated tumours lacking distinctive phenotypic features, the presence of chromosomal changes could serve as an important aid in alleviating some of the diagnostic problems encountered. The identification of consistent genetic alterations associated with certain lymphomas and
Accepted for publication 21 January 1999 
Table 1 Small round cell tumours of bone and soft tissue

Ewing sarcoma/primitive neuroectodermal tumour Intra-abdominal desmoplastic small round cell tumour

Alveolar rhabdomyosarcoma

Neuroblastoma

Small cell variant osteosarcoma

Small round cell variant malignant peripheral nerve sheath tumour

Metastatic melanoma without a known primary

Non-Hodgkin lymphoma/leukaemia

Metastatic anaplastic small cell carcinoma

Table 2 Spindle cell tumours of bone and soft tissues

Monophasic synovial sarcoma

Malignant peripheral nerve sheath tumour

Malignant fibrous histiocytoma

Fibrosarcoma

Leiomyosarcoma

Congenital fibrosarcoma

leukaemias has facilitated the diagnosis of haematological malignancy and helped to direct treatment and determine prognosis ${ }^{10}$; it is envisaged that a similar route will emerge in the management of bone and soft tissue tumours.

Cytogenetic and molecular analysis appears to be of particular value in two groups of soft tissue neoplasms: the small round cell and spindle cell tumours (tables 1 and 2). These groups are composed of fairly primitive round or spindle shaped cells, respectively, often lacking distinctive phenotypic features; despite the sophisticated histopathological methods available, chromosomal analysis aimed at detecting specific alterations appears to be the most effective variable in resolving the frequent diagnostic dilemmas.

New studies are beginning to provide increasing, and convincing, evidence that genetic variability within specific tumour groups, such as Ewing sarcoma and synovial sarcoma, may also be of prognostic value. ${ }^{11-14}$

An increasing variety of techniques is now available to detect genetic alterations in bone and soft tissue tumours, including immunohis- tochemistry for the detection of products of altered gene expression, karyotype analysis (fig 1), fluorescence in situ hybridisation (FISH) of chromosome spreads (see cover illustration of the May issue of this journal) to assess ploidy status and identify certain genetic rearrangements, Southern blotting and the polymerase chain reaction (PCR) for genomic DNA analysis, reverse transcriptase polymerase chain reaction (RT-PCR) for detecting altered mRNA products (figs 2 and 3), and DNA sequencing. ${ }^{15}$ Although a discussion of these techniques will not be attempted here, no single technique is capable of demonstrating all the genetic alterations present, and each technique serves to fulfil a specific requirement.

It is our aim in this short review to summarise our current knowledge of specific chromosomal aberrations, in particular those associated with the small round cell and spindle cell tumours, with regard to their possible diagnostic and prognostic value in clinical practice.

\section{The small round cell tumours}

The small round cell tumours of bone and soft tissues, a group of malignant tumours sharing many morphological features at a light microscopic level, comprise skeletal and extraskeletal Ewing sarcoma (including the Askin variant) and the related primitive neuroectodermal tumour (PNET), intra-abdominal desmoplastic small round cell tumour, embryonal rhabdomyosarcoma, neuroblastoma, the small round cell variant of skeletal and extraskeletal osteosarcoma, a small round cell variant of malignant peripheral nerve sheath tumour, and mesenchymal chondrosarcoma.

The differential diagnosis may be extended by the inclusion of metastatic melanoma without a known primary, non-Hodgkin lymphoma (NHL)/leukaemia, and metastatic anaplastic small cell carcinoma, all of which may have a

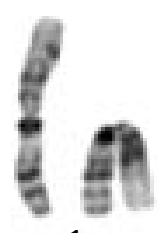

1

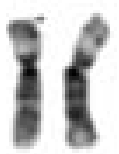

6

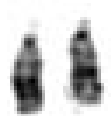

13

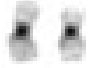

19

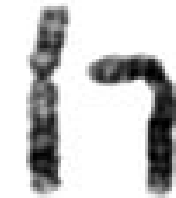

2

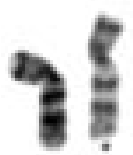

7

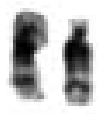

14

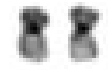

20

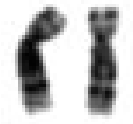

8

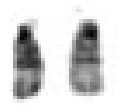

15

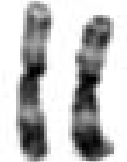

3

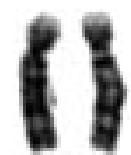

4

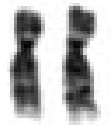

9

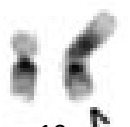

16

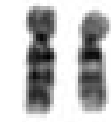

10

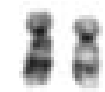

17

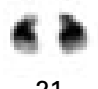

21

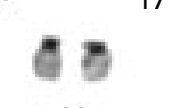

22

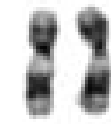

11

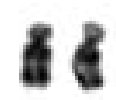

18

Y

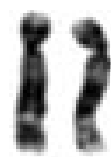

5

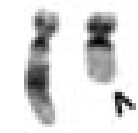

12

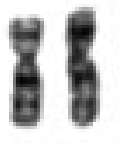

$\mathrm{X}$

$46, X X, t(12 ; 16)(q 13 ; p 11)$

Figure 1 Karyotype analysis of a myxoid liposarcoma, showing the classical $t(12 ; 16)$ reciprocal translocation (arrowheads). Courtesy of $S$ L van Zelderen-Bhola, Department of Clinical Cytogenetics, Leiden University Medical Centre. 


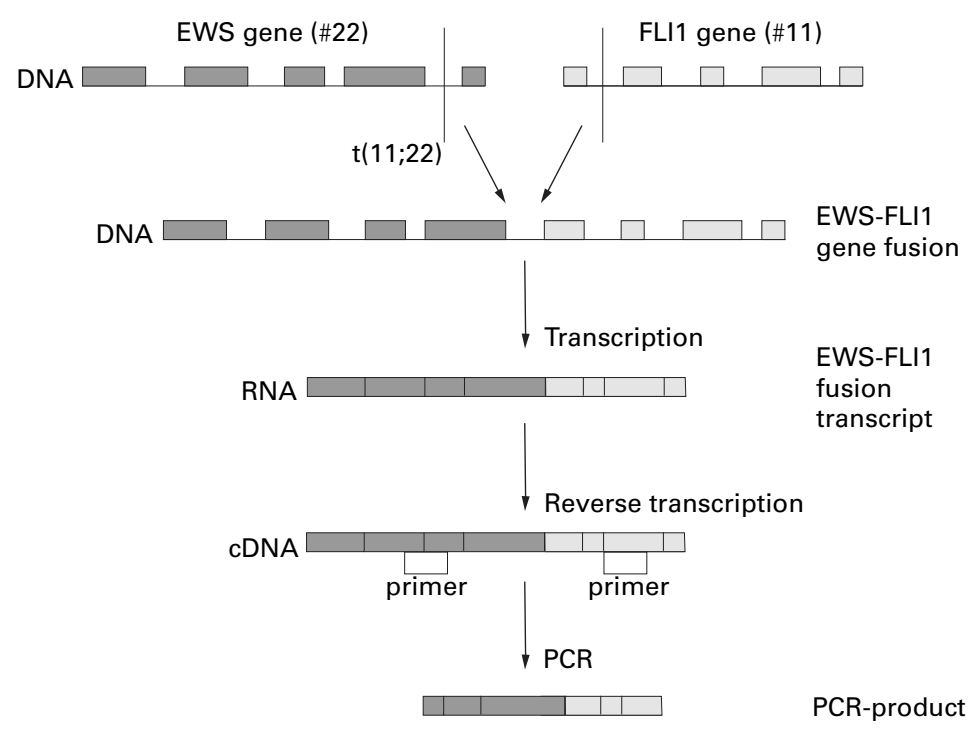

Figure 2 Schematic representation of the reverse transcriptase polymerase chain reaction (RT-PCR) reaction used for the $t(11 ; 22)$ chromosomal translocation detection in a case of the Ewing sarcoma. The chimaeric gene fusion product contains a portion of the EWS gene on chromosome 22 and the Fli1 gene on chromosome 11. Following RNA extraction from the tumour tissue, a single strand of DNA (copy-DNA or cDNA) is reverse transcribed from the $m R N A$ template using either a site specific primer or a non-specific oligo-dT primer. The cDNA strand is subsequently amplified using the PCR technique. The enzyme $D N A$ polymerase amplifies a selected segment of DNA situated between two site specific primers, one on either side of the chosen translocation to be detected. The PCR reaction will consequently only be positive if the chimaeric gene product is present.

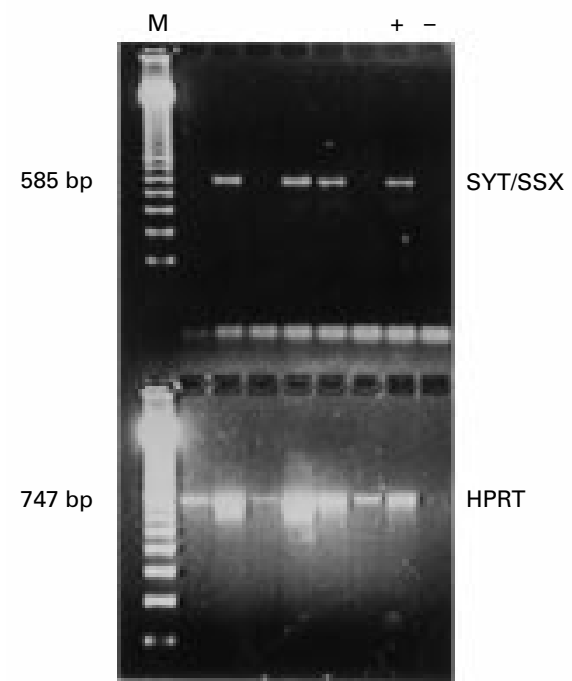

Figure 3 Reverse transcriptase polymerase chain reaction (RT-PCR) assay used to screen for the $t(X ; 18)$ translocation present in synovial sarcoma. Agarose gel electrophoresis of amplified DNA following RT-PCR to screen histologically suspected cases of synovial sarcoma for the presence of the $t(X ; 18)$ translocation, and visualised using ethidium bromide. Lane 1 of both the top and bottom gel contains a standard marker to control for PCR fragment size. While all the lanes in the bottom gel show the presence of a 747 base pair fragment derived from a ubiquitous gene used as a positive control for each RT-PCR reaction, lanes $3,5,6$, and 8 in the top gel show a 585 base pair fragment supporting the presence of the described translocation and subsequently confirmed by in situ oligonucleotide mediated hybridisation (not illustrated). The lane marked + represents a positive control, known to carry a cytogenetically proven $t(X ; 18)$ translocation; the lane marked-represents a negative control without the required template.

comparable histological phenotype (table 1). These tumours are generally composed of small primitive round to oval cells with round, often unremarkable, nuclei, usually lacking distinguishing microscopic features which might aid in facilitating histological classification. Although special stains and immunohistochemistry may be of use in determining tumour type, especially in identifying NHL/ leukaemia, and metastases from a malignant melanoma or small cell anaplastic carcinoma, it has become apparent that tumour specific genetic alterations may be very helpful in aiding the classification of those tumours that remain diagnostic dilemmas.

\section{EWING SARCOMA/PRIMITIVE NEUROECTODERMAL} TUMOUR

Ewing sarcoma of bone predominantly afflicts adolescents and young adults, showing a predilection for the pelvis and long tubular bones of the extremities. ${ }^{16}$ Primary extraskeletal Ewing sarcoma affects a similar age group, occurring predominantly in the paravertebral region, chest wall, and lower extremities. ${ }^{17}$ A specific clinical entity in the Ewing sarcoma group, the Askin tumour, is a malignant small round cell tumour of the thoracopulmonary region occurring predominantly in children, having a locally aggressive course and poor prognosis. ${ }^{18}$ The skeletal/extraskeletal Ewing sarcoma/primitive neuroectodermal tumour (PNET) family of tumours is generally believed to represent a single spectrum of neoplasms, differing only in their degree of neural differentiation. The Ewing sarcoma group lacks any degree of differentiation at a light microscopic level, while at the atypical Ewing sarcoma/PNET end, increasing neural differentiation is present, as assessed at a microscopic, immunohistochemical, and ultrastructural level. ${ }^{19}$

Immunohistochemically this family of tumours expresses p30/p32 encoded by the MIC2 gene and detectable using the monoclonal antibody O13. ${ }^{20}$ Tumours within the sarcoma group, as well as unrelated tumours, have increasingly been found to show immunoreactivity for this epitope, limiting its diagnostic use. ${ }^{21}$ Three cytogenetic translocations specific for this group have been identified to date, all involving the Ewing sarcoma gene (EWS) on the long arm of chromosome 22 (table 3 ). ${ }^{22}$ In approximately $90 \%$ of cases material is exchanged with the long arm of chromosome 11 resulting in a fusion of EWS with the friend leukaemia virus integration site 1 gene (FLI1) present at this site on chromosome 11 . In the remaining $10 \%$ of cases the translocation results in fusion of the EWS gene with the ETS related gene (ERG) on chromosome 21 or the $\underline{\mathbf{E} T S}$ translocation variant 1 gene (ETV1) gene on chromosome $7 .^{\overline{22}-25}$

The $\mathrm{t}(11 ; 22)$ translocation was the first sarcoma translocation to be cloned and characterised at the molecular level and remains the paradigm for oncogenesis in sarcomas. ${ }^{23}$ The EWS gene encodes a ubiquitous protein of unknown function containing RNA binding domains, while the FLI1, ERG, and ETV1 genes all belong to the erythroblastosis virus transforming sequence (ETS) family of transcription factor encoding genes. ${ }^{9}$ The resulting hybrid (chimaeric) protein product contains 
Table 3 Translocations of diagnostic significance in the sarcoma group

\begin{tabular}{lll}
\hline Tumour & Translocation & Genes involved \\
\hline $\begin{array}{l}\text { Ewing sarcoma/atypical Ewing } \\
\text { sarcoma/Askin tumour/PNET }\end{array}$ & $\mathrm{t}(11 ; 22)(\mathrm{q} 24 ; \mathrm{q} 12)$ & EWS/FLI1 \\
& $\mathrm{t}(21 ; 22)(\mathrm{q} 22 ; \mathrm{q} 12)$ & EWS/ERG \\
Intra-abdominal desmoplastic small & $\mathrm{t}(7 ; 22)(\mathrm{p} 22 ; \mathrm{q} 12)$ & EWS/ETV1 \\
$\quad$ round cell tumour & $\mathrm{t}(11 ; 22)(\mathrm{p} 13 ; \mathrm{q} 12)$ & EWS/WT1 \\
Clear cell sarcoma & $\mathrm{t}(12 ; 22)(\mathrm{q} 13 ; \mathrm{q} 12)$ & EWS/ATF-1 \\
Myxoid chondrosarcoma & $\mathrm{t}(9 ; 22)(\mathrm{q} 22 ; \mathrm{q} 11-12)$ & EWS/CHN \\
Alveolar rhabdomyosarcoma & $\mathrm{t}(2 ; 13)(\mathrm{q} 35 ; \mathrm{q} 14)$ & PAX3/FKHR \\
Synovial sarcoma & $\mathrm{t}(1 ; 13)(\mathrm{p} 36 ; \mathrm{q} 14)$ & PAX7/FKHR \\
Myxoid liposarcoma & $\mathrm{t}(\mathrm{X} ; 18)(\mathrm{p} 11.2 ; \mathrm{q} 11.2)$ & SYT/SSX1;SSX2 \\
Congenital fibrosarcoma & $\mathrm{t}(12 ; 16)(\mathrm{q} 13 ; \mathrm{p} 11)$ & CHOP/TLS (FUS) \\
\hline
\end{tabular}

PNET, primitive neuroectodermal tumour.

the N-terminal domain derived from EWS and a C-terminal domain of a transcription factor derived from the ETS family. ${ }^{26}$ A general hypothesis is that the chimaeric proteins represent deregulated activated transcription factors with sequence specific DNA binding domains directed towards tumour specific binding sites in the genome, and directly or indirectly influence genes responsible for the neoplastic phenotype through the EWS portion of the chimaera. ${ }^{9}$ Analysis of the predominant EWS/ FLI1 translocation has identified various breakpoints in EWS clustered between exons 7 and 10-with FLI1 showing a similar variability in breakpoints clustered between exons 5 and 8-resulting in a diversity of fusion products, of which two (types I and II) account for roughly $80 \%$ of the EWS/FLI1 hybrids. ${ }^{96}$ Similarly, several EWS/ERG variants have been identified. ${ }^{26}{ }^{27}$

Recent work is beginning to suggest that the variability in chimaeric products may be of essential use in identifying distinct risk groups within the general group of Ewing sarcoma patients and would thus impart important independent prognostic information. ${ }^{13} 142829$

The translocations described in the Ewing sarcoma/PNET family are readily demonstrable using karyotype analysis of chromosome spreads, FISH, or RT-PCR and are important for aiding or confirming accurate tumour diagnosis. ${ }^{22} 30$

Recently, the $\mathrm{t}(11 ; 22)$ translocation has been identified in a group of biphenotypic sarcomas showing both neural and myogenic features. ${ }^{31}$ Although this group of malignant ectomesenchymomas may thus appear to be related to the Ewing sarcoma/PNET group, the precise nature of the relation with respect to histogenesis and to biological and clinical behaviour is still unclear. ${ }^{9}$ Interestingly, both a putative small cell variant of osteosarcoma and a mesenchymal chondrosarcoma have been reported containing a $\mathrm{t}(11 ; 22)(\mathrm{q} 24 ; \mathrm{q} 12)$ translocation at a cytogenetic level. ${ }^{32} 33$ The breakpoint has not as yet been determined and the pathological implications and significance with respect to tumour histogenesis remain to be determined.

Numerous other non-random chromosome alterations have been identified in the Ewing sarcoma/PNET group, including trisomy 8 and trisomy 12-although these do not appear to be tumour specific and thus are not of known diagnostic or prognostic significance as yet. ${ }^{7}$
INTRA-ABDOMINAL DESMOPLASTIC SMALL ROUND CELL TUMOUR

The intra-abdominal desmoplastic small round cell tumour is a primitive sarcoma occurring predominantly in adolescent males, particularly on the serosal abdominal surfaces. It shows extreme desmoplasia and immunohistochemical positivity for epithelial, neural, and myogenic markers. ${ }^{34}$ Cytogenetic analysis has identified an invariable, non-random $\mathrm{t}(11 ; 22)$ (p13;q12) translocation which appears to be restricted to this tumour, generating a fusion between EWS on chromosome 22 and the Wilms tumour gene (WT1) on chromosome $\overline{11},{ }^{35}$ detectable by RT-PCR. ${ }^{36}$

\section{ALVEOLAR RHABDOMYOSARCOMA}

Rhabdomyosarcoma is the most common malignant mesenchymal tumour occurring under the age of 25 years. Rhabdomyosarcoma has a highly variable morphology and is subdivided into embryonal, alveolar, and pleomorphic types. Immunohistochemically these tumours may be distinguishable from other small round cell tumours by positivity for the myogenic markers and expression of the MyoD1 gene. ${ }^{37}$ Of the three subtypes generally recognised, a specific non-random genetic translocation- $\mathrm{t}(2 ; 13)(\mathrm{q} 35 ; \mathrm{q} 14)-$ has been identified in approximately $80-90 \%$ of the alveolar group, including the solid variant, ${ }^{38}$ while cytogenetic analysis of the other subtypes has not as yet identified non-random alterations. The translocation results in a fusion between the paired box 3 gene (PAX3) on chromosome $\frac{1}{2}$ and the transcription factor forkhead related gene (FKHR), also referred to as the alveolar rhabdomyosarcoma gene (ALV), on chromosome $13 .{ }^{39}$ The translocation results in an activated transcription factor containing exons from the 5' end of PAX3, encoding a DNA binding domain, joined to a portion of the forkhead DNA binding domain and additional C-terminal regions. A variant translocation- $t(1 ; 13)(\mathrm{p} 36 ; \mathrm{q} 14)$ - has been recently described in alveolar rhabdomyosarcoma involving the same FKHR gene but another gene in the PAX family, PAX $7 .{ }^{40}$ Additionally, amplification of N-myc has been detected in a large proportion of the alveolar rhabdomyosarcoma group, although the diagnostic or prognostic significance of this finding remains uncertain. ${ }^{41}$ Recent work by Kelly et al suggests that the type of PAX/FKHR transcription factor hybrid influences the clinical presentation and clinical course, that is the prognosis, within the alveolar rhabdomyosarcoma group. ${ }^{42}$

The clinical management of alveolar and embryonal rhabdomyosarcoma is somewhat different, particularly with respect to the chemotherapy regimen used, and embryonal rhabdomyosarcoma appears to have a generally better prognosis than its alveolar counterpart. ${ }^{43}$ Consequently, it is tempting to speculate about the possible prognostic significance of the lack of the $t(2 ; 13)$ translocation and lack of N-myc amplification in this group. While $\mathrm{N}$-myc amplification has also been detected in neuroblastoma and appears to correlate with an 
advanced disease state, the absence of the specific $\mathrm{t}(2 ; 13)$ translocation may facilitate in the distinction between these lesions at a molecular level in difficult cases, such as between the solid variant of alveolar rhabdomyosarcoma and embryonal rhabdomyosarcoma. ${ }^{45}$ Additionally, embryonal rhabdomyosarcoma often has a deletion of the short arm of chromosome 11, a second feature aiding the clinically important distinction between the alveolar and embryonal types of rhabdomyosarcoma. ${ }^{64}$

\section{NEUROBLASTOMA}

Neuroblastoma is one of the most common malignant tumours of childhood, exceeded only by leukaemia and brain tumours. ${ }^{46}$ The peak age of presentation is around 18 months and roughly a quarter of the cases are congenital. The majority are sporadic and only a small percentage occurs in a familial setting. ${ }^{46}$ Sites of predilection follow the distribution of the sympathetic nervous system, occurring predominantly in the paramidline between the skull and pelvis. Neuroblastoma can be clinically divided into two groups based on disease progression, and this shows a good correlation with certain genetic alterations. ${ }^{45}{ }^{47}$ The first group invariably demonstrates deletion of the short arm of chromosome 1 between 1 p 32 and 1 pter, while roughly half of the tumours are associated with $\mathrm{N}$-myc amplification. ${ }^{45}{ }^{47}$ These patients are seldom cured, even with intensive treatment. The second group has neither a deletion of the short arm of chromosome 1 nor $\mathrm{N}$-myc amplification and generally has a far better prognosis, even occasionally undergoing spontaneous regression. ${ }^{47}$ The absence of the $\mathrm{t}(2 ; 13)$ translocation present in alveolar rhabdomyosarcoma, coupled with the presence of $\mathrm{N}$-myc amplification, should facilitate distinction between these two round cell tumours. Although the described genetic alterations in neuroblastoma are not diagnostically useful owing to a lack of tumour specificity, they are of proven prognostic value and a multiplex PCR is available to assess loss of heterozygosity on chromosome $1 .^{48}$

OTHER SMALL ROUND CELL TUMOURS

The additional tumours listed in table 1 may represent diagnostic dilemmas when encountered in unusual clinical settings. Using the current histopathological methods available, including immunohistochemistry and electron microscopy, the correct diagnosis is generally apparent. Recently a novel report has appeared documenting five cases of primitive, small round cell tumours with histochemical and ultrastructural features supporting a neural line of differentiation, and without evidence of EWS chimaeric transcripts as analysed using RT-PCR; cogent arguments were put forward proposing these poorly differentiated lesions as possible variants of malignant peripheral nerve sheath tumours which may further complicate the histological assessment of the small round cell tumour group. ${ }^{49}$
The spindle cell tumours

This represents a group of histologically poorly or undifferentiated tumours including monophasic synovial sarcoma, malignant peripheral nerve sheath tumour (MPNST), so called "malignant fibrous histiocytoma (MFH)," fibrosarcoma, and leiomyosarcoma (table 2). The spindle cell tumours are composed of generally spindled cells with elongated, cigar shaped, or pointed nuclei, often making distinction on histological grounds difficult. Immunohistochemistry and electron microscopy can aid in reaching the correct diagnosis in a proportion of cases, but tumour specific genetic alterations may be particularly useful in those cases hardly classifiable on a histopathological basis alone..$^{6-9}$

\section{SYNOVIAL SARCOMA}

Synovial sarcoma, a highly malignant mesenchymal tumour predominantly of adolescents and young adults, accounts for approximately $5-10 \%$ of soft tissue sarcomas, and occurs preferentially in the extremities in the vicinity of joints, usually around the knee and in the thigh region. ${ }^{50}$ The classical biphasic variant contains both epithelioid and spindle cell components, while the more unusual monophasic variant may be composed of either epithelial or spindle cells. Additionally, roughly $20 \%$ of the tumours may be very poorly differentiated, complicating the diagnosis using routine histopathology, especially in biopsy specimens. Cytogenetic analysis has shown a non-random and highly specific $\mathrm{t}(\mathrm{X} ; 18)(\mathrm{p} 11 ; \mathrm{q} 11)$ translocation in $90-95 \%$ of all cases, irrespective of subtype. $^{5152}$ The translocation generates a fusion between the synovial sarcoma translocation gene (SYT) on chromosome 18 and either of the synovial sarcoma $\mathbf{X}$ breakpoint $\mathbf{1}$ or $\mathbf{2}$ genes ( $\overline{\mathrm{S} S X} 1$ or SSX2), two highly homologous genes on band Xp11 (53) (table 3). Several other changes appear to accompany the described translocation, ${ }^{51}$ although these are variable and not of apparent diagnostic use. Two cases of undifferentiated mesenchymal tumours, not diagnosed as synovial sarcoma, have been reported containing the $t(X ; 18)$ translocation, a fibrosarcoma, and a malignant fibrous histiocytoma. ${ }^{53}$ Since the histological distinction between various poorly differentiated sarcomas may be difficult, these reports probably represent variants of synovial sarcoma. ${ }^{8}$ Kawai et al have recently shown a significant correlation between the genotype (SYT/SSX1 or SYT/SSX2) and histological morphology, ${ }^{12}$ supporting similar earlier observations $^{54}{ }^{55}$ : translocation positive biphasic tumours tend to carry the SYT/SSX1 hybrid, while translocation positive monophasic tumours tend to carry the SYT/SSX2 variant. Additionally, Kawai et al have shown for the first time that the translocation type in translocation positive tumours has important prognostic value: the SYT/SSX2 group appear to show significantly improved metastasis-free survival time. ${ }^{12}$ The described genetic alterations are detectable using karyotype analysis and FISH, but the development of a RT-PCR 
assay is now the method of choice for establishing the correct diagnosis. ${ }^{56}$

MALIGNANT PERIPHERAL NERVE SHEATH TUMOUR Both benign and malignant neural tumours occur sporadically or in association with the hereditary neurofibromatosis syndromes. MPNST is an aggressive tumour occurring sporadically as well as in about $1-2 \%$ of patients with neurofibromatosis type I (von Recklinghausen disease, NF1). ${ }^{57}$ Although no tumour specific genetic alterations have been detected in this group, aberrations of the NF1 locus at $17 \mathrm{q} 11$ occur relatively often in this group, ${ }^{58} 59$ while loss of heterozygosity on chromosome 17 in malignant tumours in NF1 patients occurs in more than $50 \%$ of cases. ${ }^{60}$ The p53 tumour suppressor gene, although a non-specific variable, appears to be mutated in a large number of cases, the direct significance of which is unknown. ${ }^{61}$ Consequently, no diagnostic genetic methods are as yet available to identify these lesions unambiguously, and histology remains the bastion of excellence in this group.

MALIGNANT FIBROUS HISTIOCYTOMA

This remains a controversial histological soft tissue entity. A thorough and in depth review of a large group of such tumours indicated that, with extensive investigation, many of them showed some degree of differentiation, allowing classification into one of the other sarcoma groups. ${ }^{62}$ The prevailing impression is that the remaining unclassifiable lesions represent undifferentiated tumours in which possible differentiation is not identifiable using current techniques. ${ }^{62}$ p53 Mutation analysis in several of these tumours suggests that malignant fibrous histiocytoma (MFH) of bone carries a different subset of mutations from "MFH" of the soft tissue, lending support to the concept that $\mathrm{MFH}$ of bone is a separate clinical entity. ${ }^{63}$ Attempts at identifying prognostic variables in "MFH" tumours have indicated that lesions in this heterogeneous group bearing additional material on chromosome $19 \mathrm{p}$ appear to have a worse prognosis with a higher relapse rate. ${ }^{64}$

FIBROSARCOMA, LEIOMYOSARCOMA

(Non-congenital) fibrosarcomas occur anywhere in the body where fibrous tissue is found and are clustered in patients between the ages of 30 and 55 years, although any age group may be affected. Leiomyosarcomas are tumours of adults, more commonly affecting women and with a preference for retroperitoneal and abdominal sites. These malignant tumours contain a large number of random alterations which cannot be used in the clinical setting at present. ${ }^{6}$ Interestingly, a t $(12 ; 14)$ translocation has been identified in approximately $20 \%$ of uterine leiomyomas but not in its malignant counterpart. ${ }^{65}$ It remains to be ascertained whether the loci involved on chromosome 12 or 14 in these leiomyomas are altered by alternative mechanisms in leiomyosarcomas.
CONGENITAL FIBROSARCOMA

Congenital (infantile) fibrosarcoma is a rapidly growing but low grade malignant tumour occurring in neonates, infants, and small children under the age of two years and found predominantly in the extremities. The lesion has a similar morphology to its adult counterpart but has a significantly less aggressive course and a very low metastatic potential. Distinction from fibromatosis, a benign fibrous tumour, may be difficult.

Cytogenetic analysis of three cases has recently identified a novel $t(12 ; 15)(\mathrm{p} 13 ; \mathrm{q} 25)$ translocation involving the ETS translocation variant 6 (ETV6) gene (also known as TEL) at 12 p13 and the neurotropic tyrosine kinase receptor type $\mathbf{3}^{-}$(NTKR3) gene (formerly known as TRKC) at $15 \mathrm{q} 25$; the subsequent expression of a chimaeric protein tyrosine kinase is postulated to have an oncogenic potential through disruption of the signal transduction pathways. ${ }^{66}$ The tumour specificity of this translocation remains uncertain and analysis of additional cases and other tumour groups needs to be done to confirm an aetiological role in congenital fibrosarcoma. Additionally, earlier work has shown the presence of non-random genetic changes, including trisomy of chromosomes 11,17 , and 20 in cases analysed, although these changes are not specific for congenital fibrosarcoma. ${ }^{67}$

DERMATOFIBROSARCOMA PROTUBERANS

This represents a cutaneous/subcutaneous fibrohistiocytic tumour, occurring predominantly in early and mid-adult life and with a locally aggressive mode of behaviour. It has a high local recurrence rate, probably because of inadequate local excision of the extensive infiltrative margins. Very few cases have been studied cytogenetically, but a recurring $\mathrm{t}(17 ; 22)(\mathrm{q} 22 ; \mathrm{q} 13)$ translocation has been documented the significance of which is as yet uncertain. ${ }^{68}$

\section{Genetic alterations in other sarcomas}

CLEAR CELL SARCOMA OF TENDONS AND APONEUROSES

Described in 1965 by Enzinger, ${ }^{69}$ clear cell sarcoma is now a well recognised clinicopathological entity, usually targeting young adults and occurring predominantly in the extremities, often in intimate relation to the tendons or aponeuroses. The tumour has a neuroectodermal origin and may create enormous diagnostic difficulties with other round cell tumours, especially metastatic malignant melanoma to the soft tissues or bone in the absence of a known primary cutaneous lesion. ${ }^{70}$ Cytogenetic findings confirm the clinical impression that this tumour is a distinct entity; using karyotype analysis approximately $65-70 \%$ of cases contain a tumour specific translocation$\mathrm{t}(12 ; 22)(\mathrm{q} 13 ; \mathrm{q} 12)$ - which results in the fusion between the EWS gene on chromosome 22 and the activating transcription factor $\mathbf{1}$ gene (ATF-1, a transcription factor) on chromosome $12 .^{70} 71$ Additionally, it is likely that alterations at this locus may be found in a higher proportion of tumours if a more 


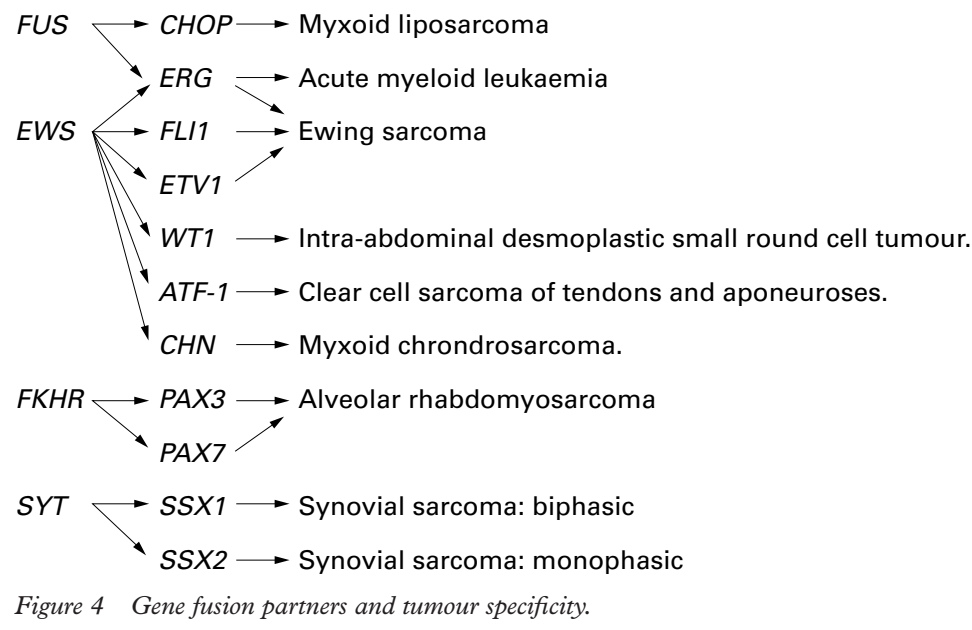

Figure 4 Gene fusion partners and tumour specificity.

sensitive assay such as RT-PCR is used. As yet, this translocation has not been detected in any other neoplasm (table 3) and is readily demonstrable using karyotype analysis, FISH, or RT-PCR. ${ }^{70}{ }^{71}$ As in the EWS family, there is variability in the exact site of the breakpoint and to date two variants have been identified, although any possible significance this may have clinically has not yet become apparent. ${ }^{70}$

LIPOSARCOMA

Liposarcomas generally arise in the retroperitoneum and thigh of adults and are divided into four groups: well differentiated, myxoid, round cell, and pleomorphic. It has been established that more than $75 \%$ of myxoid liposarcomas contain a $\mathrm{t}(12 ; 16)(\mathrm{q} 13 ; \mathrm{p} 11)$ translocation, resulting in the fusion of the CCAAT/ enhancer binding protein homologous protein gene (CHOP) on chromosome 12 and the translocated in liposarcoma gene (TLS, otherwise known as $\overline{\mathrm{FUS}}$ : fusion) on chromosome $16,{ }^{72}{ }^{73}$ and not identified in any other group of myxoid sarcomas. The CHOP/TLS fusion gene in myxoid liposarcoma appears to encode an activated transcription factor, and the mechanism of action is postulated to be similar to the EWS/ETS fusion products. ${ }^{9}$ Demonstration of the translocation is possible cytogenetically or by RT-PCR. ${ }^{74}$ The other types of liposarcoma show a variety of random genetic alterations, the significance of which is as yet unknown. ${ }^{7-9}$

Most solitary lipomas (60\%), excluding angiolipomas, have been shown to harbour cytogenetic alterations often involving a breakpoint on chromosome 12(q13-15). Interestingly, this breakpoint lies distal to the region involved in myxoid liposarcoma, but targets the same gene that is implicated in many uterine leiomyomas. ${ }^{65} 75$

Angiolipomas do not, however, appear to show cytogenetic alterations, in contrast to other lipomas, supporting the proposal that this represents a distinct group of tumours. ${ }^{76}$

CHONDROSARCOMA

Cartilaginous skeletal and extraskeletal neoplasms are a diverse group of lesions with respect to their clinical and pathological presentation. ${ }^{77}$ Of the various histological types of chondrosarcoma, only the extraskeletal myxoid group has shown a non-random $\mathrm{t}(9 ; 22)$ (q22; $111-22)$ translocation; this occurs in approximately $25 \%$ of cases in which the EWS gene is fused with the translocated in extraskeletal chondrosarcoma gene (TEC, also known as chondrosarcoma, CHN) present at 9 q22 and believed to encode an orphan nuclear receptor protein containing a zinc finger DNA binding domain, ${ }^{78}$ and detectable by RT-PCR analysis. $^{79}$

Chondrosarcomas arising from pre-existing sporadic or hereditary exostoses appear to involve the exostoses (EXT) genes located at $8 \mathrm{q} 24,11 \mathrm{p} 12$, and $19 \mathrm{p}$ which have also been implicated in the hereditary multiple exostosis syndrome, a heterogeneous autosomal dominant disease. ${ }^{80}{ }^{81}$ Recent work is beginning to indicate that p53 mutations may be correlated with increasing histological grade. ${ }^{82} 83$

\section{GASTROINTESTINAL STROMAL TUMOUR}

The gastrointestinal stromal tumour (GIST) group represents a common, usually solitary, mesenchymal tumour of the gastrointestinal tract, with variable and unpredictable biological and clinical behaviour. Recently, gain of function mutations has been identified within the c-kit proto-oncogene, which codes for a type III tyrosine kinase receptor protein (CD117), although tumour specificity remains to be determined. ${ }^{84}$

\section{General considerations and discussion}

The detection and description of apparently tumour specific genetic alterations within the sarcoma group is beginning to play an increasingly important role in unravelling and beginning to understand the molecular biology of tumorigenesis.

Interestingly, there are many structural similarities among the majority of tumour specific reciprocal translocations identified to date within the sarcomas. Gene fusion products are generated combining a gene with a putative RNA binding domain (EWS, TLS) or DNA binding domain (PAX3, PAX7) with a transcription factor gene (FLI1, ERG, ETV1, ATF-1, WT1, CHN, or FKHR). The promiscuous EWS gene on chromosome 22 is frequently involved, generating chimaeric gene fusion products with FLI1, ERG, ETV1 (Ewing sarcoma), WT1 (intra-abdominal desmoplastic small round cell tumour), ATF-1 (clear cell sarcoma), and CHN (myxoid chondrosarcoma) (fig 4). The CHOP/TLS chimaera (myxoid liposarcoma) has a similar construction. A generally held hypothesis is that while the EWS fusion partners specify DNA binding and hence tumour type, the EWS portion would regulate or deregulate RNA processing and synthesis, somehow contributing to tumorigenesis.

In addition to the genetic alterations described in this monograph, the role of tumour suppressor genes in the sarcomas is becoming clearer. p53 Gene mutations, although not tumour specific, have been detected in 30-70\% of cases of so called "malignant fibrous histiocytoma," leiomyosarcomas, rhabdomyosarco- 
mas, and liposarcomas, while these do not appear to play a role in neuroblastomas. ${ }^{85}$ Mutations in the retinoblastoma gene $(\mathrm{Rb})$ have been detected in a large proportion of high grade sarcomas unrelated to hereditary retinoblastoma, including leiomyosarcomas, "malignant fibrous histiocytomas," liposarcomas, and malignant peripheral nerve sheath tumours. ${ }^{8}$ The coinactivation of p53 and $\mathrm{Rb}$ indicates that both genes may be involved in tumorigenesis of certain sarcomas. ${ }^{8}$ Additionally the occurrence of soft tissue sarcomas as part of certain clinical syndromes such as in the Li-Fraumeni and Gardner syndromes, as yet poorly understood, is intellectually challenging and will probably generate much new information about tumour origin.

In the last decade the rapid developments in the field of molecular genetics and the increasing sophistication of laboratory techniques available to the clinician have underscored the value of the cytogenetic evaluation of bone and soft tissue tumours as an essential adjunct for accurate histopathological diagnosis. An accurate histological classification of tumour types is necessary to establish meaningful clinical trials of optimal management strategies. In addition, cytogenetic evaluation is an important tool in attempting to identify variables that may influence the clinical progression of disease and prognosis.

With the increasing identification of genes involved in translocation breakpoints, PCR and RT-PCR are increasingly becoming the methods of choice for rapid, sensitive, and specific detection of the cytogenetic and molecular alterations present in sarcomas.

For those bone and soft tissue tumours in which the non-random, specific molecular events are as yet uncrystallised, the search is continuing in awareness of the important contribution such new information will make to our ultimate understanding of tumour biology.

1 Sadler TW. Langman's medical embryology, 6th ed. Baltimore: Williams and Wilkins, 1990.

2 Enzinger FM, Weiss SW. Soft tissue tumours, 3rd ed. New York: CV Mosby, 1995.

3 Rydholm A, Berg NO, Gullberg B, et al. Epidemiology of soft tissue sarcoma in the locomotor system: a retrospective population-based study of the inter-relationships between clinical and morphological variables. Acta Pathol Microbiol Immunol Scand 1984;92A:363-74.

4 Silverberg E, Boring CC, Squires TS. Cancer statistics. $C A$ Cancer f Clin 1990;40:9-26.

5 Presant CA, Russell WO, Alexander RW, et al. Soft tissue and bone sarcoma histopathology peer review; the frequency of disagreement at diagnosis and the need for second pathology opinions: the Southeastern Cancer Study Group experience. $\mathcal{F}$ Clin Oncol 1986;4:1658-61.

6 Fletcher JA. Cytogenetics and molecular biology of soft tissue tumors. In: Weiss SW, Brooks JSJ, eds. Soft tissue
tumours, chapter 2. New York: Williams and Wilkins, 1996.

7 Fletcher JA, Kozakewich HP, Hoffer FA, et al. Diagnostic relevance of clonal cytogenetic aberrations in malignant soft tissue tumors. $N$ Engl $₹$ Med 1991;324:436-42.

8 Sreekantaiah C, Ladanyi M, Rodriguez E, et al. Chromosomal aberrations in soft tissue tumors. Am f Pathol 1994; 144:1121-34.

9 Ladanyi $M$. The emerging molecular genetics of sarcoma translocations. Diagn Mol Pathol 1995;4:162-73.

10 Melo JV. The diversity of bcr-abl fusion proteins and their relationship to leukaemia phenotype. Blood 1996;88:237584.

11 Sandberg AA. The chromosomes in human cancer and leukaemia, 2nd ed. New York: Elsevier, 1990.

12 Kawai A, Woodruff J, Healey JH, et al. SYT-SSX gene fusion as a determinant of morphology and prognosis in synovial sarcoma. $N$ Engl f Med 1998;338:153-60.

13 Zoubeck A, Dockhorn-Dworniczak B, Delattre O, et al. Does expression of different EWS chimeric transcripts define clinically distinct risk groups of Ewing tumor patients? F Clin Oncol 1996;14:1245-51.

14 Rabbitts TH. The clinical significance of fusion oncogenes in cancer. N Engl f Med 1998;338:192-4.

15 Alberts B, Bray D, Lewis J, et al. Molecular biology of the cell, 2nd ed. New York: Garland Publishing, 1993.

16 Pritchard DJ, Dahlin DC, Dauphine RT, et al. Ewing's sarcoma: a clinicopathological and statistical analysis of patients surviving 5 years or longer. J Bone Joint Surg Am 1975;57A:10-16.

17 Angervall L, Enzinger FM. Extraskeletal neoplasm resembling Ewing's sarcoma. Cancer 1975;36:240-51.

18 Askin FB, Rosai J, Sibley RK, et al. Malignant small cell tumour of the thoracopulmonary region in childhood. Cancer 1979;43:2438-51.

19 Pagani A, Fischer-Colbrie R, Eder U, et al. Neural and mesenchymal differentiations in Ewing's sarcoma cell lines. Morphological, immunophenotypic, molecular biologica and cytogenetic evidence. Int $\mathcal{F}$ Cancer 1995;63:738-43.

20 Fellinger EJ, Garin-Chesa P, Triche T, et al. Immunohistochemical analysis of Ewing's sarcoma cell surface antigen p30/p32 MIC2. Am f Pathol 1991;139:317-25.

21 Stevenson AJ, Chatten J, Bertoni F, et al. CD99 (p30/ $32 \mathrm{mic} 2$ ) neuroectodermal/Ewing's sarcoma antigen as an immunohistochemical marker: review of more than 600 tumours and the literature experience. Appl Immunohistochem 1994;2:231-40.

22 Delattre O, Zucman J, Melot T, et al. The Ewing family of tumors-a subgroup of small-round-cell tumors defined by specific chimeric transcripts. N Engl f Med 1994;331:294-

23 Delattre O, Zucman J, Plougastel B, et al Gene fusion with an ETS DNA-binding domain caused by chromosome translocation in human tumours. Nature 1992;359:162-5.

24 Sorensen PH, Lessnick SL, Lopez-Terrada D, et al. A second Ewing's sarcoma translocation, $\mathrm{t}(21 ; 22)$, fuses the EWS gene to another ETS-family transcription factor, ERG. Nature Genet 1994;6:146-51.

25 Jeon IS, Davis JN, Braun BS, et al. A variant Ewing's sarcoma translocation $(7 ; 22)$ fuses the EWS gene to another ETS gene, ETV1. Oncogene 1995;10:1229-34.

26 Meier VS, Kuhne T, Jundt G, et al. Molecular diagnosis of Ewing tumours: improved detection of EWS-FLI-1 and EWing tumours: improved detection of EWS-FLI-1 and EWS-ERG chimaeric transcripts and rapid determination
of exon combinations. Diagn Mol Pathol 1998;7:29-35.

27 Giovannini M, Biegel JA, Serra M, et al. EWS-ERG and EWS-FLI1 fusion transcripts in Ewing's sarcoma and primitive neuroectodermal tumors with variant translocations. F Clin Invest 1994;94:489-96.

28 de Alava E, Kawai A, Healey JH, et al. EWS-FLI1 fusion transcript structure is an independent determinant of prognosis in Ewing's sarcoma. F Clin Oncol 1998;16:124855.

29 Ewing's sarcoma oncogene structure: a novel prognostic marker? [Editorial] 7 Clin Oncol 1998;16:1241-3.

30 Downing JR, Head DR, Parham DM, et al. Detection of the $(11 ; 22)$ (q24;q12) translocation of Ewing's sarcoma and peripheral neuroectodermal tumor by reverse transcriptase polymerase chain reaction. Am f Pathol 1993;143:1294polym

31 Sorenson PHB, Shimada H, Liu XF, et al. Biphenotypic sarcomas with myogenic and neural differentiation express the Ewing's sarcoma EWS/FLI1 fusion gene. Cancer Res 1995; 55:1385-92

32 Noguera R, Navarro S, Triche TJ. Translocation $(11 ; 22)$ in small cell osteosarcoma. Cancer Genet Cytogenet 1990;45: $121-4$.

33 Sainati L, Scapinello A, Montaldi A, et al. A mesenchymal chondrosarcoma of a child with the reciprocal translocation $(11 ; 22)(\mathrm{q} 24 ; \mathrm{q} 12)$. Cancer Genet Cytogenet 1993;71:144-7.

34 Gerald WL, Miller HK, Battifora $\mathrm{H}$, et al. Intra-abdominal desmoplastic small round-cell tumor. Report of 19 cases of a distinctive type of high-grade polyphenotypic malignancy involving young individuals. Am f Surg Pathol 1991;15: $499-513$

35 Gerald WL, Rosai J, Ladanyi M. Characterisation of the genomic breakpoint and chimeric transcripts in the EWSWT1 gene fusion of desmoplastic small round cell tumor. Proc Natl Acad Sci USA 1995;92:1028-32.

36 de Alava E, Ladanyi M, Rosai J, et al. Detection of chimeric transcripts in desmoplastic small round cell tumor and related developmental tumors by reverse transcriptase polymerase chain reaction. Am f Pathol 1995;147:1584-91.

37 Dias P, Parham DM, Shapiro DN, et al. Myogenic regulatory protein (MyoD1) expression in childhood solid tumors: diagnostic utility in rhabdomyosarcoma. Am f Pathol 1990;137:1283-91.

38 Barr FG, Biegel JA, Sellinger B, et al. Molecular and cytogenetic analysis of chromosomal arms $2 \mathrm{q}$ and $13 \mathrm{q}$ in alveolar rhabdomes Chromosomes Cancer 1991;3:153-61.

39 Barr FG, Galli N, Hollick J, et al. Rearrangement of the PAX3 paired box in the pediatric solid tumor alveolar rhabdomyosarcoma. Nature Genet 1993;3:113-17.

40 Davis RJ, D'Cruz CM, Lovell MA, et al. Fusion of PAX7 to FKHR by the variant $\mathrm{t}(1 ; 13)$ (p36; q14) translocation in alveolar rhabdomyosarcoma. Cancer Res 1994;54:2869-72.

41 Dias P, Kumar P, Marsden HB, et al. N-myc gene is amplified in alveolar rhabdomyosarcomas (RMS) but not in embryonal RMS. Int $\mathcal{F}$ Cancer 1990;45:593-6.

42 Kelly KM, Womer RB, Sorensen PHB, et al. Common and variant gene fusions predict distinct clinical phenotypes in rhabdomyosarcoma. F Clin Oncol 1997;15:1831-6. 
43 Shimada H, Newton WA, Soule EH, et al. Pathology of fatal rhabdomyosarcoma: report of intergroup rhabdomyosar-

44 Scrable H, Witte D, Shimada H, et al. Molecular differential pathology of rhabdomyosarcoma. Genes Chromosomes Cancer 1989;1:23-35.

45 Brodeur GM, Seeger RC, Schwab M, et al. Amplification of $\mathrm{N}$-myc in untreated human neuroblastoma correlates with advanced disease stage. Science 1984;224:1121-4.

46 De Lorimer AA, Bragg KU, Linden G. Neuroblastoma in childhood. Am f Dis Child 1969;118:441-50.

47 Caron $\mathrm{H}$, van Sluis $\mathrm{P}$, de Kraker J, et al. Allelic loss of chromosome $1 \mathrm{p}$ as a predictor of unfavourable outcome in patients with neuroblastoma. $N$ Engl f Med 1996;334:22530 .

48 Schleiermacher G, Peter M, Michon J, et al. A multiplex PCR assay for routine evaluation of deletion of the short arm of chromosome 1 in neuroblastoma. Eur $f$ Cancer 1995;31A:535-8.

49 Abe S, Imamura T, Park P, et al. Small round-cell type of malignant peripheral nerve sheath tumour. Mod Pathol malignant periph

50 Schmidt D, Thum P, Harms D, et al. Synovial sarcoma in adults and children: a report from the Kiel paediatric tumour registry. Cancer 1991;67:1667-72.

51 Turc-Carel C, Dal Cin P, Limon J, et al. Involvement of chromosome $\mathrm{X}$ in primary cytogenetic change in human neoplasia: nonrandom translocation in synovial sarcoma. Proc Natl Acad Sci USA 1987;84:1981-5.

52 Clark J, Rocques PJ, Crew AJ, et al. Identification of novel genes, SYT and SSX, involved in the $\mathrm{t}(\mathrm{X} ; 18)(\mathrm{p} 11.2 ; \mathrm{q} 11.2)$ translocation found in human synovial sarcoma. Nature Genet 1994;7:502-8.

53 Mandahl N, Helm S, Arheden K, et al. Multiple karyotypic rearrangements including $\mathrm{t}(\mathrm{X} ; 18)(\mathrm{p} 11 ; \mathrm{q} 11)$ in a fibrosarcoma. Cancer Genet Cytogenet 1988;30:323-7.

54 de Leeuw B, Suijkerbuijk RF, Olde Weghuis D, et al. Distinct Xp11.2 breakpoint regions in synovial sarcoma revealed by metaphase and interphase FISH: relationship to histologic subtypes. Cancer Genet Cytogenet 1994;73:89to his.

55 Renwick PJ, Reeves BR, Dal Cin P, et al. Two categories of synovial sarcoma defined by divergent chromosome translocation breakpoints in Xp11.2, with implications for the histologic sub-classification of synovial sarcoma. Cytogene Cell Genet 1995;70:58-63.

56 Argani P, Zakowski MF, Klimstra DS, et al. Detection of the SYT-SSX chimeric RNA of synovial sarcoma in paraffinembedded tissue and its application in problematic cases. Mod Pathol 1998;11:65-71.

57 Sorensen SA, Mulvihill JJ, Nielson A. Longterm follow-up of von Recklinghausen neurofibromatosis. $N$ Engl f Med 1986;314:1010-15

58 Mertens F, Rydholm A, Bauer HF, et al. Cytogenetic findings in malignant peripheral nerve sheath tumours. Int f Cancer 1995;61:793-8.

59 Jhanwar SC, Chen Q, Li FP, et al. Cytogenetic analysis of soft tissue sarcomas. Recurrent chromosomal abnormalities in malignant peripheral nerve sheath tumours ties in malignant peripheral nerve sheath tum

60 Skuse GR, Kosciolek BA, Rowley PT. Molecular genetic analysis of tumors in von Recklinghausen neurofibromatosis:loss of heterozygosity for chromosome 17. Genes Chromosomes Cancer 1989;1:36-41.

61 Legius E, Dierick $\mathrm{H}$, Wu R, et al. TP53 mutations are frequent in malignant NF1 tumors. Genes Chromosomes Cancer 1994;10:250-5.

62 Fletcher CDM. Pleomorphic malignant fibrous histiocytoma: fact or fiction. Am f Surg Pathol 1992;16: 213-28.

63 Taubert H, Berger D, Hinze R, et al. How is the mutational status for tumor suppressors p53 and p16INK4A in $\mathrm{MFH}$ of the bone? Cancer Lett 1998;123:147-51.

64 Rydholm A, Mandahl N, Heim S, et al. Malignant fibrous histiocytomas with a $19 \mathrm{p}+$ marker chromosome have increased relapse rate. Genes Chromosomes Cancer 1990;2: increas 296 .
65 Schoenmakers EFPM, Wanschura S, Mols R, et al. Recurrent rearrangements in the high mobility group proein gene, HMGI-C, in benign mesenchymal tumours. Nature Genet 1995;10:436-43.

66 Knezevich SR, McFadden DE, Tao W, et al. A novel ETV6NTRK3 gene fusion in congenital fibrosarcoma. Nature Genet 1998;18:184-7.

67 Sankary S, Dickman PS, Wiener E, et al. Consistent numerical chromosome aberrations in congenital fibrosarcoma. Cancer Genet Cytogenet 1993;65:152-6.

68 Pedeutour F, Simon MP, Minoletti F, et al. Translocation, $\mathrm{t}(17 ; 22)$ (q22;q13), in dermatofibrosarcoma: a new tumour-associated chromosomal rearrangement. Cytogenet Cell Genet 1996:72:171-4.

69 Enzinger FM. Clear cell sarcoma of tendons and aponeuroses: an analysis of 21 cases. Cancer 1965;18:116374.

70 Graadt van Roggen JF, Mooi WJ, Hogendoorn PCW. Clear cell sarcoma of tendons and aponeuroses (malignant melanoma of soft parts) and cutaneous melanoma: exploring the histogenetic relationship between these two clinicopathological entities. F Pathol 1998;186:3-7.

71 Zucman J, Delattre O, Desmaze C, et al. EWS and ATF-1 gene fusion induced by $\mathrm{t}(12 ; 22)$ translocation in malignant melanoma of soft parts. Nature Genet 1993;4:341-5.

72 Sreekantaiah C, Karakousis CP, Leong SP, et al. Cytogenetic findings in liposarcoma correlate with histologic subtypes. Cancer 1992;69:2484-95.

73 Turc-Carel C, Limon J, Dal CP, et al. Cytogenetic studies of adipose tumours. Recurrent reciprocal translocation $\mathrm{t}(12$; 16)(q13;p11) in myxoid liposarcomas. Cancer Genet Cytogenet 1986;23:291-9.

74 Panagopoulos I, Mandahl N, Ron D, et al. Characterisation of the CHOP breakpoints and fusion transcripts in myxoid liposarcomas with the 12;16 translocation. Cancer Res 1994;54:6500-3.

75 Ashar HR, Fejzo MS, Tkachenko A, et al. Disruption of the architectural factor HMG-C1: DNA-binding A-T hook motifs fused in lipomas to distinct transcriptional regulatory domains. Cell 1995;82:57-65.

76 Sciot R, Akerman M, Dal Cin P, et al. Cytogenetic analysis of subcutaneous angiolipoma: further evidence supporting its difference from ordinary pure lipomas. Am $\mathcal{F}$ Surg Pathol 1997;21:441-4

77 Bridge JA, Bhatia PS, Anderson JR, et al. Biological and clinical significance of cytogenetic abnormalities in benign and malignant cartilaginous lesions. Cancer Genet Cytogenet 1993;69:79-90.

78 Labelle Y, Zucman J, Stenman G, et al. Oncogenic conversion of a novel orphan nuclear receptor by chromosome translocation. Hum Mol Genet 1995;4:2219-26.

79 Brody RI, Ueda T, Hamelin A, et al. Molecular analysis of the fusion of EWS to an orphan nuclear receptor gene in extraskeletal myxoid chondrosarcoma. Am f Pathol 1997; 150:1049-58.

80 Hecht JT, Hogue D, Strong LC, et al. Hereditary multiple exostosis and chondrosarcoma: linkage to chromosome 11 and loss of heterozygosity for EXT linked markers on chromosome 11 and 8. Am F Hum Genet 1995;56:1125-31.

81 Raskind WH, Conrad EU, Chansky H, et al. Loss of heterozygosity in chondrosarcomas for markers linked to hereditary multiple exostoses foci on chromosome 8 and 11. Am f Hum Genet 1995;56:1132-9.

82 Nawa G, Veda T, Mori S, et al. Prognostic significance of Ki-67 (MIB 1) proliferation index and p53 overexpression in chondrosarcomas. Int 7 Cancer 1996;69:86-91.

83 Terek RM, Healey JH, Garin-Chesa P, et al. p53 Mutations in chondrosarcoma. Diagn Mol Pathol 1998;7:51-6.

84 Hirota S, Isozaki K, Moriyama Y, et al. Gain-of-function mutations of c-kit in human gastrointestinal stromal tumours. Science 1998;279:577-80.

85 Komuro H, Hayashi Y, Kawamura M, et al. Mutations of the p53 gene are involved in Ewing's sarcomas but not in neuroblastoma. Cancer Res 1993;53:5284-8. 